\title{
Complement Lysis of Human Erythrocytes
}

\author{
DIFFERING SUSCEPTIBILITY OF TWO TYPES OF PAROXYSMAL \\ NOCTURNAL HEMOGLOBINURIA CELLS TO C5b-9
}

\author{
Charles H. Packman, Stephen I. Rosenfeld, David E. Jenkins, Jr., Patricia \\ A. THIEM, and JoHN P. LEDDY, Department of Medicine, University of \\ Rochester School of Medicine and Dentistry, Rochester, New York, 14642; \\ Nashville Regional Red Cross Blood Center, Vanderbilt University School \\ of Medicine, Nashville, Tennessee 37203
}

\begin{abstract}
A B S T RACT Although enhanced sensitivity of erythrocytes to complement-mediated lysis is a hallmark of paroxysmal nocturnal hemoglobinuria (PNH), subpopulations of erythrocytes in such patients vary significantly in this respect. One PNH erythrocyte subpopulation (termed type III) comprises exquisitely sensitive cells, whereas type II PNH erythrocytes are intermediate in complement sensitivity between PNH type III and normal human erythrocytes. Differences in the action of the terminal complement components that would account for the differing lytic behavior of types II and III PNH erythrocytes have been proposed but not directly demonstrated.

The present studies, making use of carefully selected cases with pure populations of type II or type III erythrocytes, confirm a prior observation that antibodycoated PNH erythrocytes of both types II and III display comparably supranormal C3 binding in whole human serum. However, when lysis was induced by the isolated C5b-9 membrane attack mechanism, bypassing the requirement for $\mathrm{C} 3$ binding, only type III PNH cells exhibited greater than normal lysis. This finding suggests that type III PNH erythrocytes have an additional membrane abnormality not present in type II cells. Thus, the differing lytic behavior of these two cell types in whole serum may reflect the additive effects on type III cells of both exaggerated C3 binding and enhanced sensitivity to C5b-9, whereas the more moderate lysis of type II PNH cells may be determined mainly or entirely by the earlier-acting mechanism producing augmented C3 binding.
\end{abstract}

Address reprint requests to Dr. Packman, University of Rochester Medical Center.

Received for publication 21 December 1978 and in revised form 16 April 1979.
The failure of guinea pig $\mathrm{C} 8$ and $\mathrm{C} 9$, as opposed to human $\mathrm{C} 8$ and $\mathrm{C} 9$, to reveal the true lytic sensitivity of PNH-III E in our earlier study is illustrated, and its implications briefly discussed.

\section{INTRODUCTION}

In patients with paroxysmal nocturnal hemoglobinuria $(\mathrm{PNH})^{1}$ three subpopulations of erythrocytes (E) occur, differing in their sensitivity to hemolysis by human antibody (Ab) and fresh human serum $(1,2)$. Type III PNH E (PNH-III) are 15-25 times as sensitive as normal E, whereas the sensitivity of type II PNH E (PNH-II) is 3-5 times normal. Type I PNH E resemble normal E. Various combinations of these $\mathrm{E}$ populations may be found in individual PNH patients; a few patients appear to have essentially pure populations of a given type $(1,2)$.

Both PNH-II E (3) and PNH-III E (4-7) have been found to bind more $\mathrm{C} 3$ than do normal $\mathrm{E}$ in several hemolytic systems employing whole serum as complement (C) source; however, only PNH-III E displayed supranormal lysis for a given level of C3 binding (3). The latter observation led to the hypothesis that an additional mechanism, acting beyond the $\mathrm{C} 3$ step, may therefore be responsible for the increased lysis of PNH-III E over PNH-II E (3). Indeed, Gotze and Müller-Eberhard (8) had found earlier that PNH E (type not specified) were more sensitive than normal human $\mathrm{E}$ to $\mathrm{Ab}$-free bystander lysis initiated by fluid

\footnotetext{
${ }^{1}$ Abbreviations used in this paper: $\mathrm{Ab}$, antibody; $\mathrm{C}$, complement; E, erythrocytes; EAC1-7 ${ }^{\text {hu }}$ or EC5b-7 hu, erythrocytes bearing hemolytically active human $\mathrm{C} 1-7$ or $\mathrm{C} 5 \mathrm{~b}-7$ complexes, respectively; GVBE, Veronal-buffered saline containing $0.1 \%$ gelatin and $0.02 \mathrm{M}$ EDTA; PNH, paroxysmal nocturnal hemoglobinuria; ZS, serum-activated zymosan.
} 
phase $\overline{\mathrm{C} 423}$ in the presence of C5-C9. Similar findings were reported in 1974 by Tedesco et al. (9) using a reactive lysis system. In these latter studies $(8,9)$ no attempt was made to study single populations of PNH E, or to explore possible terminal lytic differences between PNH-II and PNH-III E. The present report examines the latter question through study of the responses of single populations of type II and type III PNH E to functionally pure C5-C9 in hemolytic systems designed to bypass the abnormality in C3 binding.

\section{METHODS}

Cells. Fresh blood from group O PNH patients and normal donors was obtained on the same day and stored in Alsever's solution at $4^{\circ} \mathrm{C}$ for up to $4 \mathrm{wk}(6)$. Some experiments were performed on $\mathrm{E}$ reconstituted from frozen storage (10); their behavior was comparable to fresh $\mathrm{E}$ in parallel experiments.

$C$ components. Human $\mathrm{C} 5$ was isolated by the method of Nilsson et al. (11). Human C6, C7, C8, and C9, as well as guinea pig C8 and C9, were purchased from Cordis Laboratories Inc., Miami, Fla. Human C5b6 was prepared by the method of Yamamoto and Gewurz (12). For some initial experiments, purified C5b6 was kindly supplied by $\mathrm{Dr}$. $\mathrm{H}$. Gewurz and Dr. T. Lint (Rush Medical College, Chicago, Ill.).

C lysis sensitivity tests were performed by the method of Rosse (2) using heat-inactivated $\left(56^{\circ} \mathrm{C}, 60 \mathrm{~min}\right)$ human antisera: immunoglobulin (Ig)M anti-I cold agglutinins (Chad), or iso-immune anti-Tj ${ }^{\mathrm{a}}$ (IgM and IgG). Sensitization of $E$ with anti- $\mathrm{j}^{\mathrm{a}}$ was carried out at room temperature for $20 \mathrm{~min}$.

Measurements of cell-bound C3. Normal, PNH-II, and PNH-III E were sensitized by exposure to equal quantities of anti-Tja $\left(22^{\circ} \mathrm{C}, 20 \mathrm{~min}\right)$, and aliquots of each type of $\mathrm{Ab}-$ sensitized E (EA) were exposed to equal amounts of diluted whole human serum as $\mathrm{C}$ source. Lysis was determined by hemoglobin release, and cell-bound C3 was quantitated using ${ }^{125}$ I-labeled goat anti-human C3. This test has a high reproducibility (coefficient of variation, $4.2 \%$ ) (10).

Zymosan-initiated bystander lysis. After the general method of Lint et al. (13), serum-activated zymosan (ZS) was prepared by incubating boiled, washed Z (ICN Nutritional Biochemicals Corp., Cleveland, Ohio) with fresh human serum for $1 \mathrm{~h}$ at $17^{\circ} \mathrm{C}$. $\mathrm{ZS}$ was washed and suspended to 25 $\mathrm{mg} / \mathrm{ml}$ in Veronal-buffered saline containing $0.1 \%$ gelatin and $0.02 \mathrm{M}$ EDTA (GVBE), pH 6.5. After incubation for $1 \mathrm{~h}$ at $37^{\circ} \mathrm{C}$ to allow dissociation of loosely adherent $\mathrm{C} 5 \mathrm{~b} 67 \mathrm{com}$ plexes, ${ }^{2}$ the $\mathrm{ZS}$ was washed again. $0.8 \mathrm{mg} \mathrm{ZS}$ and $4 \times 10^{7} \mathrm{E}$ were mixed in GVBE, $\mathrm{pH} 6.5$, centrifuged, and the buffer discarded. $\mathrm{C} 5$ and $\mathrm{C} 6\left(30 \mathrm{CH}_{50} \mathrm{U}\right.$ of each in $0.1 \mathrm{ml}$ of $0.02 \mathrm{M}$ EDTA) were added to the pellet, which was resuspended and incubated at $37^{\circ} \mathrm{C}$ for $10 \mathrm{~min}$. Addition of $\mathrm{C} 7(25 \mathrm{U})$ was followed by another 10-min incubation. The cells were then washed thrice in GVBE, $\mathrm{pH} 7.4$, and the pellet suspended in $1 \mathrm{ml}$ of the same buffer. Aliquots $(0.1 \mathrm{ml})$ of these EC5b67 were added to $0.2 \mathrm{ml}$ of a mixture of $\mathrm{C8}(6 \mathrm{U})$ and $\mathrm{C} 9(10-40 \mathrm{U})$ and incubated $1 \mathrm{~h}$ at $37^{\circ} \mathrm{C}$ with constant shaking. Degree of lysis was determined by OD at $413 \mathrm{~nm}$. Spontaneous cell lysis was determined by substituting GVBE, pH 7.4, for C8 and C9. $100 \%$ lysis was achieved by adding $\mathrm{NH}_{4} \mathrm{OH}, 0.04 \%$, to an aliquot of each test-cell mixture.

${ }^{2}$ Rosenfeld, S. I., C. H. Packman, and J. P. Leddy. Unpublished observations.
Reactive lysis. Human C5b6, $50 \mu \mathrm{l}$ in appropriate dilution determined by prior experiment, was added to $4 \times 10^{7} \mathrm{E}$ in $0.4 \mathrm{ml}$ GVBE, pH 6.5. C7, $25 \mathrm{U}$, was added and the mixture incubated at $37^{\circ} \mathrm{C}$ for $10 \mathrm{~min}$. After 3 washes in GVBE, pH 7.4 , the cells were suspended in $1 \mathrm{ml}$ of that buffer. Aliquots $(0.1 \mathrm{ml})$ were then handled in the same manner as EC5b67 prepared with ZS particles.

\section{RESULTS}

Homogeneity of PNH E populations. The C lysis sensitivity test was used to survey a group of PNH patients, from which three patients were selected for detailed study. As illustrated in Fig. 1, patients $R$ and $\mathrm{L}$ both appeared to possess a single population of highly sensitive (PNH-III) E, and patient $\mathrm{K}$ appeared to have a single population of type II $\mathrm{E}$ with intermediate $\mathrm{C}$ sensitivity. Similar results were obtained using anti-I cold agglutinin as Ab source. Note that the lysis of the PNH-II E is clearly greater than that of normal $E$ at all $\mathrm{C}$ inputs, and lysis of PNH-III E is higher than that of PNH-II throughout the dosage range.

C3 binding. To confirm that our samples of PNH-II $\mathrm{E}$ and PNH-III E conformed to the behavior previously described by Rosse et al. (3-5) for these cell types, C3 binding was studied under conditions comparable to those in Fig. 1. As shown in Table I, C3 binding was equal for the PNH-II and PNH-III E, i.e., $\cong 9-15$ times the normal mean, although PNH-III E lysed to

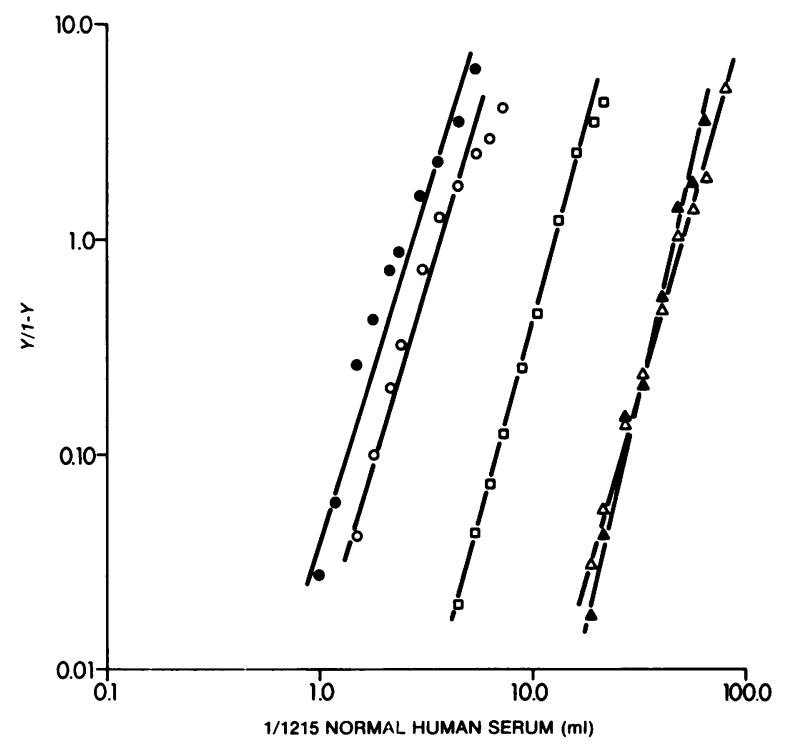

FIGURE 1 Complement lysis sensitivity tests on erythrocytes from PNH patients $R(\Theta)$, L (O), and $K(\square)$ and from normal donors $P(\Delta)$ and $N(\Delta)$. The erythrocytes were sensitized with heat-inactivated $1 / 4$ human isoimmune anti- $\mathrm{j}^{\mathrm{a}}$. Input of human serum (as complement source) is expressed as the equivalent volume of the highest dilution employed. Varying inputs of serum dilutions ranging from $1 / 15$ to $1 / 1,215$ were actually used, in a reaction volume of $1.5 \mathrm{ml}$ containing $2 \times 10^{7} \mathrm{EA}$. Y represents percent lysis. 
TABLE I

${ }^{125}$ I-Anti-C3 Uptake by Normal Human and PNH E Exposed to Equal Quantities of $\mathrm{Ab}$ * and Fresh Human Serum

\begin{tabular}{llcc}
\hline Expt.f & \multicolumn{1}{c}{ Cell type tested } & Lysis & Uptake ${ }^{125 I-a n t i-C 3 \$}$ \\
\hline \multirow{4}{*}{ I } & & $\%$ & \\
& PNH-III, patient L & 97 & 5,680 \\
& PNH-II, patient K & 78 & 5,750 \\
& Normals (3) & $0,0,0$ & $422 ; 606 ; 628$ \\
II & PNH-III, patient R & 97 & 1,932 \\
& PNH-III, patient L & 92 & 3,292 \\
& PNH-II, patient K & 51 & 2,212 \\
& Normals (3) & $0,0,0$ & $275 ; 150 ; 246$ \\
\hline
\end{tabular}

* Optimally diluted (1/4), heat-inactivated human iso-immune anti-Tja.

$\ddagger$ In experiment I the quantity of serum $\mathrm{C}$ employed was sufficiently great that the differences between PNH-II and PNH-III E in percent lysis are somewhat masked. Experiment II uses a smaller input of serum $\mathrm{C}$ to bring out the true differences.

$\S$ Expressed as $\mathrm{ng} / 5 \times 10^{7}$ erythrocytes.

a greater extent. Normal $\mathrm{E}$ did not lyse and bound very little C3.

Action of C5b-9. Our earliest studies on bystander lysis of normal human and PNH E (14) used guinea pig C8 and C9 in the final step. This was based on our standard practice in hemolytic $\mathrm{C}$ titrations in which sheep erythrocytes bearing hemolytically active human C1-7 (EAC1-7 ${ }^{\text {hu}}$ ) are lysed most effectively by guinea pig C8 and C9. Subsequently, we discovered a rather striking difference when human C8 and C9 were substituted for guinea pig components. Four representative experiments are summarized in Table II. It is apparent that, using guinea pig terminal $\mathrm{C}$ components, the difference in lytic response between normal and PNH-III $\mathrm{E}$ is minimal, whereas human C8 and C9 reveal large differences in sensitivity to lysis. All subsequent studies described below used human $\mathrm{C}$ components exclusively.

Fig. 2 shows the responses of normal human, sheep, PNH-II, and PNH-III E in ZS-initiated bystander lysis by $\mathrm{C} 5-\mathrm{C} 9$ as a function of relative $\mathrm{C} 9$ concentration. PNH-III E (and also sheep E) clearly exhibit greater lysis than normal $\mathrm{E}$ for a given input of $\mathrm{C}$, whereas the lysis of PNH-II E are within the normal range. Similar results were obtained when the concentrations of C5 and C6 were varied, and C7-C9 concentrations were held constant.

Fig. 3 depicts representative results in the reactive lysis system initiated by purified human C5b6. In this experiment, lysis is plotted as a function of C5b6 input in the presence of constant C7-C9 concentration. Again, PNH-III E lyse to a greater extent than normal $\mathrm{E}$, and lysis of PNH-II $\mathrm{E}$ is equal to normal. Completely comparable results were obtained using varied C9 input with constant concentrations of other reactants.

In many experiments, with both systems, lysis of PNH-III E from both patients ranged up to five times normal, whereas lysis of the PNH-II E consistently overlapped the responses of normal $\mathrm{E}$.

\section{DISCUSSION}

Our observations with the $\mathrm{C}$ lysis sensitivity test (Fig. 1 and other experiments not shown) confirm the existence of as many as three subpopulations of $E$ in patients with $\mathrm{PNH}$, as originally identified by Rosse and Dacie $(1,2)$. In view of the differing responses of these $\mathbf{E}$ subpopulations to C-mediated injury, it seems clear that the relative percentages of these $\mathrm{E}$ types in a given patient's blood must be taken into account in studies on the PNH defect. Each of the 3 patients whose E were used for the present studies exhibited single

TABLE II

Lysis of PNH-III and Normal Human EC5b-7 by Guinea Pig or Human C8 and C9

\begin{tabular}{lllrl}
\hline \multirow{2}{*}{$\begin{array}{l}\text { Species source } \\
\text { of C8 and C9 }\end{array}$} & $\begin{array}{c}\text { Cell type used } \\
\text { to form EC5b-7nu* }\end{array}$ & Mean \pm SD & (Range) & \\
\cline { 3 - 4 } & & $\%$ & & \\
Guinea pig & PNH-III & $31 \pm 10$ & $(16-39)$ & NS $\$$ \\
& Normal & $24 \pm 8$ & $(17-34)$ & \\
Human & PHN-III & $80 \pm 9$ & $(76-93)$ & $P=0.025 \S$ \\
& Normal & $21 \pm 9$ & $(7-27)$ & \\
\hline
\end{tabular}

\footnotetext{
* EC5b- $7^{\text {hu }}$, formed in the standard ZS bystander system using human C5, C6, and $\mathrm{C} 7$, were washed and incubated with functionally pure C8 and C9 from the species indicated (see Methods).

t Based on four experiments.

$\S$ Mann-Whitney U test.
} 


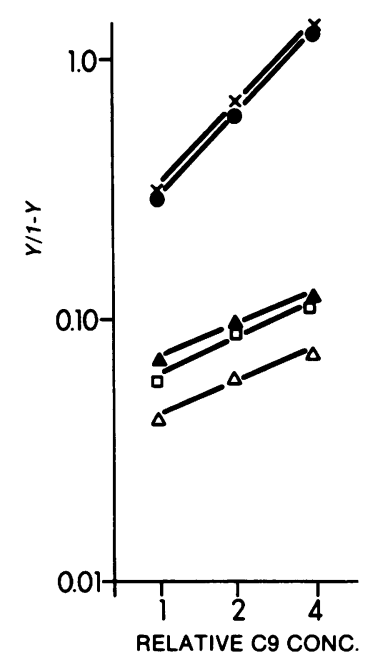

FIGURE 2 ZS-initiated bystander lysis of unsensitized E from normal humans $\mathbf{P}$ and $\mathbf{N}(\Delta, \Delta)$, PNH-II patient $\mathrm{K}(\square)$, and PNH-III patient $R(O)$. Representative responses of sheep $E(X)$ are shown for comparison. In this experiment lysis was studied over a range of $\mathrm{C} 9$ concentrations (conc.) with constant input of ZS and C5-C8.

populations of C-sensitive cells: $>95 \%$ PNH-III for patients $\mathrm{R}$ and L, and $>95 \%$ PNH-II for patient K(Fig. 1).

The bystander and reactive lysis systems permit a study of erythrocyte responses to the membrane attack mechanism of $\mathrm{C}$, independent of the $\mathrm{C}$ activation mechanisms and their inhibitors. In the bystander system, C5 convertase on surrogate particles (ZS complexes)

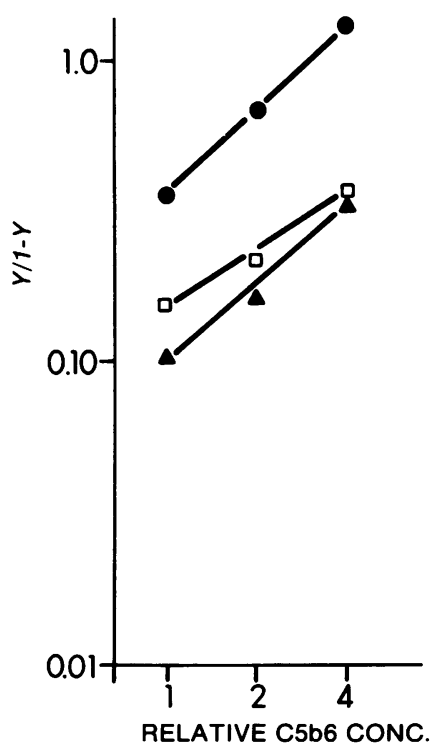

FIGURE 3 C5b,6-initiated reactive lysis of unsensitized

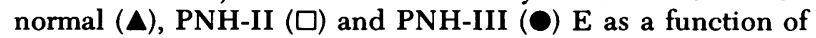
increasing C5b,6 input (constant C7-C9). The symbols employed refer to the same subjects as in Figs. 1 and 2. Conc., concentration. allows generation of C5b67 in the fluid phase with secondary passive uptake by target E, forming EC5-7. The latter are potentially susceptible to lysis by $\mathrm{C} 8$ and C9. In the reactive lysis system, incubation of target $\mathrm{E}$ with purified, preformed $\mathrm{C} 5 \mathrm{~b} 6$ and $\mathrm{C} 7$ also generates EC5-7 which, again, may be lysed by C8 and C9. The historical, theoretical, and immunochemical basis for this type of lysis has been well documented by others $(8,12,15-20)$. In the present context, these hemolytic systems bypass the effects (on lysis) of the exaggerated $\mathrm{C} 3$ binding exhibited by both PNH-II and PNH-III E in whole serum (Table I) (3-7) and allow isolated study of the effects of C5b-9 on each cell type.

Our initial studies of bystander lysis using guinea pig C8 and C9 led us to the conclusion that PNH-III and normal $\mathrm{E}$ were equally sensitive to C5b-9 attack (14). Subsequently, we discovered that when human C8 and C9 are substituted for guinea pig C8 and C9, PNH-III E consistently lyse to a greater extent than normal E (Table II and Figs. 2 and 3). In the present studies, which used only human $\mathrm{C}$ components, $\mathrm{PNH}-$ III $\mathrm{E}$ exhibited a three- to fivefold increased sensitivity to C5b-9 compared to normal, whereas PNH-II E were similar to normal E (Figs. 2 and 3).

The latter observation stands in contrast to the results obtained in hemolytic systems permitting formation of C3 and C5 convertases directly on the test erythrocytes. In classical pathway mediated lysis initiated by antibody in the presence of fresh whole serum (Table I) (3), as well as alternative pathway mediated lysis $^{3}$ (3), types II and III PNH E exhibit the same degree of supranormal C3 binding. Nevertheless, in both systems, the degree of lysis of PNH-II E is consistently intermediate between that of PNH-III $\mathrm{E}$ and normal human E (Fig. 1) (3).

The critical observation (3) that PNH-III E but not PNH-II E achieve supranormal lysis for a given amount of C3 bound, could indicate either $(a)$ that a greater proportion of the bound C3 contributes to C5 convertase formation on PNH-III E than on PNH-II E; or $(b)$ that PNH-III E differ from PNH-II E in being more sensitive to the lytic effects of C5b-9. Gotze and Müller-Eberhard (8) had reported earlier that although PNH E bound $>3$ times as much $\mathrm{C} 5$ as normal $\mathrm{E}$, the degree of lysis for a given number of cell-bound C5 molecules was the same. Inasmuch as the type(s) of the PNH E tested was not determined, these observations (8) did not address the issue of the differing lytic behavior of PNH-II vs. PNH-III E; however, these findings did suggest that the hemolytic efficiency of

\footnotetext{
${ }^{3}$ Jenkins, D. E., Jr., R. M. Johnson, W. H. Moore, R. C. Hartmann, and C. L. Posman. Uptake of ${ }^{125} I$ anti-C3 and ${ }^{125} I$ anti-C4 by normal and paroxysmal nocturnal hemoglobinuria erythrocytes following incubation in the acid hemolysis and sucrose hemolysis reaction systems. Submitted for publication.
} 
bound C5b-9 was not enhanced for whatever PNH cell type was tested. More recently, Roualt et al. (21) approached this question indirectly by counting the number of electron microscopic (EM) ring lesions produced on PNH-III $\mathrm{E}$ and normal $\mathrm{E}$ at equivalent degrees of lysis; PNH-II E were not studied. These authe rs observed that, at $40-50 \%$ lysis, many more EM lesions were produced on normal $\mathrm{E}$ than on PNH-III E. This finding was interpreted to mean that PNH-III E are abnormally sensitive to the terminal lytic mechanism. Our studies, comparing PNH-II and PNH-III E in concurrent experiments and in systems that avoid potential differences in C5 convertase formation, now provide direct evidence in support of alternative $b$ above. That is, the PNH-III E, but not the PNH-II E, were abnormal in their susceptibility to C5b-9 attack.

The mechanism of the greater lytic sensitivity of PNH-III E to C5b-9 may involve either increased binding of C5b-7, more efficient conversion of membrane-bound C5b-7 to lytic lesions by C8 and C9, or a combination of these effects. Further studies are underway to elucidate these points. The observation, noted above, that human $\mathrm{C} 8$ and $\mathrm{C} 9$, but not guinea pig C8 and C9, can bring out the differing lytic responses of PNH-III E and normal E suggests that some of the events relevant to this difference are occurring during the final stages of the membrane attack mechanism.

As a result of the present findings and previous data $(3,21)$, it appears likely that there are at least two functional abnormalities in the interaction of PNH E with $\mathrm{C}$ : (a) increased binding of $\mathrm{C} 3$ for a given $\mathrm{C}$ input, and $(b)$ increased sensitivity to C5b-9 attack. Enhanced C3 binding, shared by PNH-II and PNH-III E, is probably involved in enhanced formation of $\mathrm{C} 5$ convertase with its attendant potential for initiating assembly of greater numbers of E-bound C5b-9 complexes. This abnormality could wholly account for the enhanced sensitivity of PNH-II E to Ab-initiated lysis. A combination of this mechanism and enhanced sensitivity to C5b-9 attack appears to account for the still greater lysis of PNH-III E by Ab and whole serum.

\section{ACKNOWLEDGMENTS}

The superb technical assistance of Jill K. Countryman and Deborah Beyer is acknowledged with sincere gratitude. W. Hugh Moore skillfully performed the ${ }^{125}$ I-anti-C3 uptake studies. We also thank Sally Ann Hart for preparation of the manuscript.

This work was supported by U. S. Public Health Service grants R23-HL22742, RO1-AI12568, TO1-AI00028, PO1HL18208, and HL11816-RR95 with matching funds from the American National Red Cross. The opinions and assertions are those of the authors and do not necessarily bear relationship to the policies or views of the American Red Cross.

\section{REFERENCES}

1. Rosse, W. F., and J. F. Dacie. 1966. Immune lysis of normal human and paroxysmal nocturnal hemoglobinuria (PNH) red blood cells. I. The sensitivity of PNH red cells to lysis by complement and specific antibody. J. Clin. Invest. 45: 736-744.

2. Rosse, W. F. 1973. Variations in the red cells in paroxysmal nocturnal hemoglobinuria. Br. J. Haematol. 24: $327-342$.

3. Rosse, W. F., J. P. Adams, and A. M. Thorpe. 1974. The population of cells in paroxysmal nocturnal haemoglobinuria of intermediate sensitivity to complement lysis: significance and mechanism of increased immune lysis. Br. J. Haematol. 28: 181-190.

4. Logue, G. L., W. F. Rosse, and J. P. Adams. 1974. Mechanisms of immune lysis of red blood cells in vitro. I. Paroxysmal nocturnal hemoglobinuria cells. J. Clin. Invest. 52: 1129-1137.

5. Rosse, W. F., G. L. Logue, J. Adams, and J. H. Crookston. 1974. Mechanisms of immune lysis of the red cells in hereditary erythroblastic multinuclearity with a positive acidified serum test and paroxysmal nocturnal hemoglobinuria. J. Clin. Invest. 53: 31-43.

6. Jenkins, D. E., Jr., W. N. Christenson, and R. L. Engle, Jr. 1966. Detection of complement components on the unlysed erythrocytes from acid hemolysis and thrombin test systems in paroxysmal nocturnal hemoglobinuria. J. Clin. Invest. 45: 796-802.

7. Jenkins, D. E., Jr., R. M. Johnson, and R. C. Hartmann. 1970. Uptake of anti-C4 and anti-C3 by erythrocytes from paroxysmal nocturnal hemoglobinuria hemolytic systems. J. Clin. Invest. 49: 49 a (Abstr.)

8. Gotze, O., and H. J. Müller-Eberhard. 1970. Lysis of erythrocytes by complement in the absence of antibody. J. Exp. Med. 132: 898.

9. Tedesco, F., R. Corrocher, E. Jirrillo, and G. deSandre. 1974. Reactive hemolysis test in paroxysmal nocturnal hemoglobinuria. Haematologia. 49: 292-297.

10. Jenkins, D. E., Jr., R. M. Johnson, and W. H. Moore. 1978. Radioactive antiglobulin testing with ${ }^{125} \mathrm{I}$ anti-C4 and anti-C3. Transfusion (Phila.). 18: 407-416.

11. Nilsson, U. R., R. H. Tomar, and F. B. Taylor, Jr. 1972. Additional studies on human C5: development of a modified purification method and characterization of the purified product by polyacrilamide gel electrophoresis. Immunochemistry. 9: 709-723.

12. Yamamoto, K., and H. Gewurz. 1978. The complex of C5b and C6: isolation, characterization and identification of a modified form of C5b consisting of three polypeptide chains. J. Immunol. 120: 2008-2015.

13. Lint, T. F., C. L. Behrends, P. J. Baker, and H. Gewurz. 1976. Activation of the complement attack mechanism in the fluid phase and its control by C567-Inh: lysis of normal erythrocytes initiated by zymosan, endotoxin, and immune complexes. J. Immunol. 117: 1440-1446.

14. Packman, C. H., S. I. Rosenfeld, D. E. Jenkins, Jr., and J. P. Leddy. 1978. Studies on the lytic sensitivity of paroxysmal nocturnal hemoglobinuria erythrocytes. J. Immunol. 120: 1790. (Abstr.)

15. Thompson, R. A., and P. J. Lachmann. 1970. Reactive lysis: the complement mediated lysis of unsensitized cells. I. The characterization of the indicator factor and its identification as C7. J. Exp. Med. 131: 629-642.

16. Lachmann, P. J., and R. A. Thompson. 1970. Reactive lysis: the complement mediated lysis of unsensitized 
cells. II. The characterization of activated reactor as C56 and the participation of C8 and C9. J. Exp. Med. 131: 643-657.

17. Kolb, W. P., J. A. Haxby, C. M. Arroyave, and H. J. MüllerEberhard. 1972. Molecular analysis of the membrane attack mechanism of complement. J. Exp. Med. 135: $549-566$.

18. Goldman, J. N., S. Ruddy, and K. F. Austen. 1972. Reaction mechanisms of nascent C $\overline{567}$ (reactive lysis). I. Reaction characterization for production of EC567 and lysis by C8 and C9. J. Immunol. 109: 353-359.
19. Podack, E. R., W. P. Kolb, and H. J. Müller-Eberhard. 1976. The C5b-9 complex: subunit composition of the classical and alternative pathway generated complex. J. Immunol. 116: 1431-1434.

20. Podack, E. R., G. Biesecker, W. P. Kolb, and H. J. MüllerEberhard. 1978. The C5b-6 complex: reaction with $\mathrm{C} 7$, C8, C9. J. Immunol. 121: 484-490.

21. Roualt, T. A., W. F. Rosse, S. Bell, and J. Shelburne. 1978. Differences in the terminal steps of complement lysis of normal and paroxysmal nocturnal hemoglobinuria red cells. Blood. 51: 325-330. 